Thorax, 1979, 34, 284-285

\title{
A double-blind trial of bromocriptine in steroid dependent asthma
}

\author{
K M CHRISTENSEN, H LETMAN, AND A G MIKKELSEN
}

From Chest Clinic, Aalborg Sygehus and Medical Department, Middelfart Sygehus, Denmark

The pilot study of Newman Taylor et al (1976) in which, by adding bromocriptine to the full medical treatment, they improved the symptoms of three out of four asthmatic patients, prompted us to carry out this study. Bromocriptine is a dopaminergic agonist that is used in acromegalic patients, as well as an inhibitor of prolactin in doses of 5 to $20 \mathrm{mg}$ a day. We decided to use $15 \mathrm{mg}$ a day, which is usually without major side effects.

\section{Methods and results}

The trial was designed as a controlled doubleblind cross-over study with bromocriptine (A) against placebo (B). Patients were randomised in two parallel groups for treatment in combinations $\mathrm{A}-\mathrm{B}$ and $\mathrm{B}-\mathrm{A}$.

The bromocriptine and placebo capsules were identical. In each period the drug was given in an initial dose of one capsule $(2.5 \mathrm{mg})$ a day and was slowly increased to two capsules three times a day. Each patient received each preparation for 12 weeks. Between the two periods the initial medical treatment was given for one week.

The clinical effect of the treatment was evaluated by:

(1) Titrating the oral daily dose of prednisone by reducing the actual dose by $2.5 \mathrm{mg}$ a day if the patient improved. In cases of deterioration the prednisone dose was increased.

(2) Actual decrease/increase in additional symptomatic bronchodilator requirements (xanthines and beta-2-stimulating drugs) were registered for each treatment period. Each additional tablet, suppository, or aerosol inhalation was considered as one dose.

(3) Change in daily peak flow rate (PEF), measured by the patients before the first and last daily medical intake.

Wilcoxon's matched paired signed rank test for differences was used with the bromocriptine period as positive rank against the placebo period.

The 23 outpatients (12 from the chest clinic, Aalborg County Hospital and 11 from the medical department, Middelfart Hospital) were all patients with longstanding chronic asthma in whom the conventional treatment with aminophylline and beta-2-stimulating drugs had to be supplemented $x$ by oral prednisone for at least six months before ${ }_{\perp}^{\omega}$ the trial. (Eleven of the patients also received a $i$ beclomethasone inhaler.) All patients gave in- $\infty$ formed consent to participating in the trial. Three patients left the trial for reasons unconnected $\frac{}{5}$ with bromocriptine. Twenty patients (10 men, $10 \vec{\rightarrow}$ women) were finally included in the study. 음 Age range was 33 to 75 years, mean 55.6. Mean daily prednisone dose before the trial was $10.65 \mathrm{mg}$.

The mean daily prednisone dose and the mean daily dose of bronchodilators did not differ between the two treatment periods and the average $\bar{D}$ daily PEF did not differ between the two periods (see table).

\section{Discussion}

The lung contains large concentrations of dopamine, but the part played by this substance is not known. A possible relation between bronchialo asthma and low dopamine concentration has been $\underset{\otimes}{\mathscr{D}}$ suggested by Barbeau (1970), who showed an extremely low urinary excretion of dopamine in 3 . many patients with asthma. Three patients who had required corticosteroid for more than two years were treated with a daily dose of $3 \mathrm{~g}$ levo-o dopa for from three to nine months. In two patients the required dose of corticosteroids waso decreased from an average of $30 \mathrm{mg}$ a day to less than $5 \mathrm{mg}$. A similar hypothesis was the back-or ground of the pilot study by Newman Taylor et $N$ al (1976) of four patients with disabling asthma, who failed to respond to conventional treatment $\sigma$ with bronchodilators and corticosteroids. Bromocriptine was given in a maintenance dose of $20 \mathrm{mg}$ a day. This treatment permitted a reduction in the $\cong$ dose of corticosteroids and a decrease in symptomatic bronchodilator requirements in three patients, while the fourth patient showed no $\mathbb{\otimes}$ improvement. However, in our controlled study, $\frac{\mathbb{D}}{\mathbb{Q}}$ bromocriptine, a dopamine agonist, did not pro- $\frac{0}{\sigma}$ duce any improvement in the condition of severe corticosteroid-dependent asthmatic patients. 
Daily dosage of prednisone and bronchodilators with PEF measurements

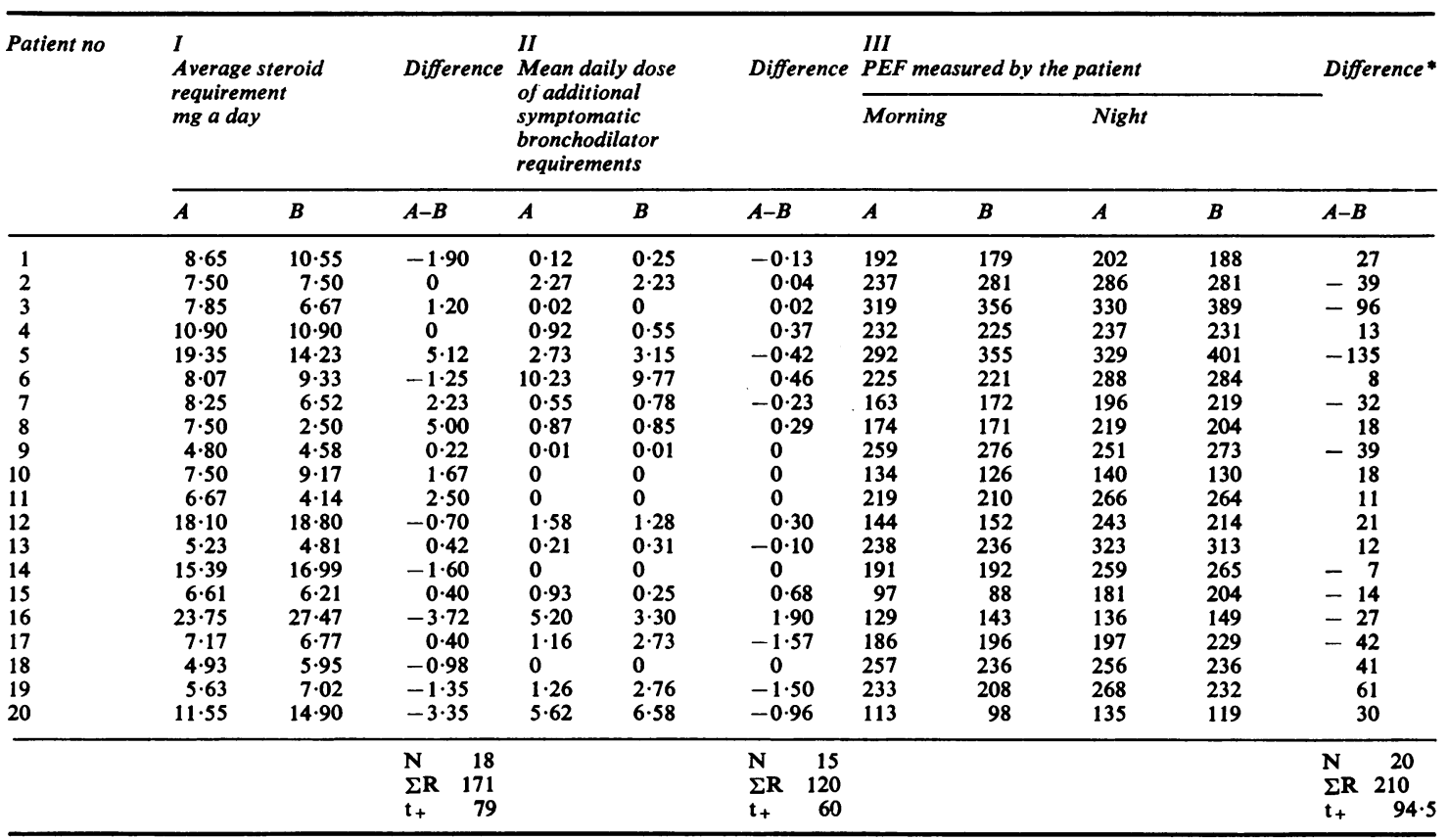

A = Bromocriptine period; $B=$ Placebo period.

*Difference of morning + night values of PEF in periods $A$ and $B$.

We thank Professor J Fabricius for reviewing the statistics and Hanne Enevoldsen for typing the manuscript.

\section{References}

Barbeau, A (1970). Dopamine and disease. Canadian Medical Association Journal, 103, 824-832.
Newman-Taylor, A J, Soutar, C, Shneerson, J, and Turner-Warwick, M (1976). Bromocriptine in the treatment of intractable asthma. Thorax, 31, 488.

Requests for reprints to: $\operatorname{Dr} \mathrm{K} M$ Christensen, Lungeklinikken, Aalborg Sygehus afsnit SYD, DK9000 Aalborg. 